\title{
A noção de estrutura em linguística: uma impactante (e decisiva) repercussão
}

Luiza Milano*

\section{Resumo}

O presente artigo parte da leitura do texto "Estrutura" em linguistica, publicado originalmente em 1962, e presente em Problemas de linguística geral I, de Émile Benveniste. O objetivo é buscar entender a conjuntura em que esse escrito foi elaborado, focando principalmente no movimento intelectual europeu dos anos 1950 e 1960 para refletir sobre o estatuto epistemológico do termo estrutura nos estudos linguísticos da época.

Palavras-chave: Epistemologia da linguística. Estrutura. Estruturalismo.
$\mathrm{O}$ presente artigo tem como ponto de partida o texto de Benveniste intitulado "Estrutura" em linguística, publicado originalmente em 1962, e presente na coletânea Problemas de Linguística Geral I (BENVENISTE, 1991), organizada pelo autor em 1966. No entanto, como o estudioso da obra benvenistiana já está acostumado a fazer, para melhor se acompanhar a reflexão ali presente, é importante estabelecer um diálogo desse texto com outros escritos do autor, a fim de que se tenha um panorama mais amplo do percurso nele apresentado. Nesse sentido, cabe apontar de início que, no presente artigo, serão visitados, além do já destacado "Estrutura” em linguística, as seguintes publicações do linguista sírio: Tendências recentes em linguística geral (1954); Vista d'olhos sobre o desenvolvimento da linguística (1963); Saussure após meio século (1963); Estrutura-

Professora do Departamento de Letras Clássicas e Vernáculas da Universidade Federal do Rio Grande do Sul. Professora e orientadora do Programa de Pós-graduação em Letras da mesma Universidade. E-mail: luizamilanos@gmail.com

Data de submissão: set. 2018 - Data de aceite: out. 2018 http://dx.doi.org/10.5335/rdes.v14i3.8555 
lismo e linguística (1968); Estrutura da língua e estrutura da sociedade (1968), Semiologia da língua (1969), O aparelho formal da enunciação (1970), Últimas aulas no Collège de France (1968-1969).

Benveniste (1991) inicia o texto "Estrutura" em linguística questionando o uso dos termos estrutura - estrutural - estruturalista. Obviamente, nós ainda hoje nos debatemos também com os múltiplos desdobramentos daquilo que se tornou ou que passou a ser nomeado como estrutura, assim como noções dela derivadas. Mas precisamos, antes de problematizarmos as noções acima elencadas, pensar no contexto de produção desse texto de Benveniste, que foi publicado pela primeira vez no ano de 1962 .

Antes de mais nada, é preciso circunscrevermos o ambiente da época. A virada da década de 1950 para a de 1960 foi efervescente para a intelectualidade europeia. Recém havia tido na França importantes eventos que colocavam a noção de estrutura no centro na discussão. Um desses eventos, em 1957, abordava a "Noção de estrutura e estrutura do conhecimento" (o referido evento foi organizado pela Editora Albin Michel). Dois anos mais tarde, em 1959, sob o comando do epistemólogo Jean Piaget, do sociólogo Lucien Goldmann e do filósofo Maurice de Gandillac, outro importante evento colocava o foco nas "Noções de gênese e estrutura”. E, também nesse mesmo ano, tem lugar o evento organizado pelo então jovem sociólogo Roger Bastide cuja temática era "Sentidos e usos do termo estrutura". E é nesse colóquio que Ben- veniste, então, apresenta as reflexões de "Estrutura" em linguística que lemos em Problemas de Linguística Geral I. O texto em questão já havia sido publicado originalmente em 1962 pela Editora Mouton, em uma reunião dos trabalhos apresentados no evento de Bastide.

Vemos aí uma efervescência intelectual europeia entre o final da década de 1950 e início da década de 1960 em que, sob diferentes prismas, a noção de estrutura - e seus desdobramentos técnicos, teóricos, empíricos, metodológicos, didáticos, filosóficos e até mesmo religiosos (no caso, no sentido de "pregação de uma verdade") estavam epistemologicamente ganhando contornos.

Importante também é sublinhar o engajamento de Benveniste nesse momento cultural e nesse contexto de discussões acerca da noção de estrutura. Em 1961, à época do lançamento da revista L'Homme - um marco no campo da antropologia estrutural francesa -, Lévi-Strauss convida o geógrafo tropicalista Pierre Gourou e nosso estimado linguista Émile Benveniste para estarem à frente do projeto da revista junto com ele. Não é demais lembrar que Benveniste havia feito parte da banca da tese de doutoramento de Lévi-Strauss, em 1948. Nesse sentido, cabe acompanharmos o depoimento tocante de Lévi-Strauss, em carta a Roman Jakobson. Esse registro encontra-se no livro "Correspondance", que traz a troca de cartas entre Lévi-Strauss e Jakobson, lançado em maio de 2018. Marc Lebiez ${ }^{1}$, ao comentar a troca de correspondências entre esses dois 
pensadores, sublinha a referência à figura de Émile Benveniste nelas presente: Lévi-Strauss surge (falando de si nessas cartas) um pouco mais sobre o que nos atrevemos a chamar de suas dificuldades institucionais, pois ele parece ter mostrado uma eficiência formidável nessa área. É impressionante que ele (Lévi-Strauss) poderia ter sido eleito ao Collège de France já em 1949, aos 41 anos, mas foi derrotado por três votos. Ele atribui esse "tropeço" provisório ao fato de que seus amigos Benveniste e Dumézil muito certos de seu sucesso, "negligenciaram uma campanha adversa" que era menos dirigida contra sua pessoa do que para o benefício de outra disciplina, a história da arte. Conforme destaca ainda Marc Lebiez, todas evocações do nome de Benveniste nessa cartas são acompanhadas de observações lisonjeiras, tanto do seu colega linguista Jakobson como por parte de Lévi-Strauss, que viu nele o único membro do júri de sua tese capaz de entender o que ele queria fazer (sic) ${ }^{2}$.

O que queremos destacar com isso é que o artigo "Estrutura" em linguística não é fruto de uma reflexão avulsa ou solitária. Benveniste estava engajado no centro da convulsão estruturalista europeia dos anos 1950 e 1960 . E, bem sabemos, o fato de a linguística assumir o papel de carro-chefe do estruturalismo joga sobre Benveniste e demais linguistas contemporâneos seus uma responsabilidade enorme. Jacques Lacan fala disso inclusive para justificar sua decepção quando encomenda um artigo a ele e acaba por se desagradar com o resultado ${ }^{3}$.
Mas, voltando ao foco do texto benvenistiano "Estrutura" em linguística, vemos que o autor estabelece o percurso a ser ali traçado anunciando que na discussão sobre a noção de estrutura levará em consideração especificamente a linguística europeia de língua francesa (e anotando inclusive, nesse próprio texto, remissão a outro texto seu presente em Problemas de linguística geral I, Tendências recentes em linguística geral, de 1954).

Benveniste avisa/lembra que, nos registros até então conhecidos sobre o mestre genebrino, Saussure não havia utilizado o termo "estrutura", mas "sistema", como bem sabemos. Essa observação, como se pode ver na publicação das "Últimas Aulas"4, segue acompanhando Benveniste até o fim: a herança saussuriana e a abordagem da língua como sistema.

No texto de 1962, Benveniste atribui a origem do termo "estrutura" aos integrantes do Círculo Linguístico de Praga (1926, 1928, 1929), os conhecidos russos de Praga. Benveniste cita Troubetzkoy que apontava que a abordagem estrutural era a tendência de todas as ciências daquela época. Especificamente sobre o estudo dos sons das línguas, em um texto datado de 1933, "A fonologia atual", Troubetzkoy diz: "A fonologia atual é caracterizada, sobretudo, por seu estruturalismo e seu universalismo sistemático".

Benveniste lembra que em 1939 a Revista Acta Linguística: Revista Internacional de Linguística Estrutural (de Copenhague) é fundada com forte sustentação de princípios estruturais. 
Aponta Viggo Bröndal (que na revista cita a definição de estrutura proposta por Lalande) e Louis Hjelmslev como importantes expoentes desse pensamento. No entanto, Benveniste não chega a fazer o registro de uma informação um tanto significativa sobre a ocorrência da expressão "estrutura", provavelmente a primeira de que se tem notícia no campo da linguística, em um livro sobre o verso tcheco, de 1923, de autoria de Roman Jakobson $^{5}$. Obviamente esse texto de Jakobson sobre o verso tcheco não teve grande circulação (o que não desqualifica seu registro). Mas o mesmo não se pode dizer da publicação conhecida como as Teses de 29 - texto inaugural do Círculo Linguístico de Praga e fruto do I Congresso de Filólogos Eslavos - na qual termo aparece explicitamente, conforme será apontado a seguir. $\mathrm{O}$ primeiro item desse documento tem como título "Problemas metodológicos decorrentes da concepção de língua como sistema e importância de tal concepção para as línguas eslavas". Há, em seguida, quatro subseções:

a. Concepção de língua como sistema funcional;

b. Tarefas do método sincrônico. Suas relações com o método diacrônico;

c. Novas possibilidades de utilização do método comparativo;

d. Lei de encadeamento dos fatos de evolução linguística.

Não é o objetivo do presente artigo detalhar cada um desses tópicos, então optaremos por ir diretamente ao ponto de interessa da seguinte constatação: pode-se perceber, nos tópicos do documento, fortes indícios de uma passagem da noção de sistema para a de estrutura, o que sabemos, teve as consequências epistemológicas que teve. Os linguistas de Praga partem de uma visão sincrônica de língua como sistema apontando justamente seu aspecto funcional. No entanto, ao apresentarem o "método" de análise proposto, vão apontar a necessidade de se descobrir as "leis de estrutura dos sistemas linguísticos e da sua evolução" (TOLEDO, 1978, p. 83, grifos nossos). Lê-se, então, três vezes, na mesma página do documento: "leis de estrutura dos sistemas linguísticos", "línguas diferenciadas em função da sua estrutura", e "consequências da comparação estrutural de línguas aparentadas" (TOLEDO, 1978, grifos nossos). Sublinhamos: isso está presente no texto inaugural do Círculo Linguístico de Praga, datado de 1929.

Após empreender uma série de leituras e mergulhar em estudos sobre a noção de estrutura em e ao redor de Benveniste é surpreendente reler a proposta, por exemplo, de outro importante artigo do autor como a que aparece em "Estrutura da língua e estrutura da sociedade" (texto de 1968). Naquele texto, Benveniste está dizendo que, embora seja possível fazer uma leitura da estrutura da língua e da estrutura da sociedade, o laço entre elas não é o de uma correlação estrutural. E, pelo que apontam os estudos benvenistianos acerca da "Semiologia 
da Língua" (BENVENISTE, 1989, p. 43), justamente aí encontra-se toda a leitura da relação de interpretância entre diferentes sistemas semiológicos. Enfim, talvez aqui esteja uma bela ilustração de que a noção de estrutura não é necessariamente um vírus ou um monstro que veio contaminar, que se espalhou e cegou (ou ensurdeceu) tantos linguistas. A noção de estrutura, sem dúvida, foi um operador que alavancou significativamente a cientifização do campo dos estudos da linguagem, mas acreditamos que se pode constatar que há alguns linguistas que tomaram o devido cuidado com o alcance e com as limitações dessa noção, no decorrer de sua trajetória. $\mathrm{E}$ Benveniste, obviamente, é um deles. Se ela (a estrutura) é um modelo, ou um ponto de vista importante, isso não quer dizer que seja uma noção aplicável ou replicável em toda e qualquer análise de um sistema (o linguístico, por exemplo) a ser empreendida. Nem mesmo que ela baste para explicar todas as variáveis de um fenômeno simbólico tão multifacetado, seja ele a linguagem, a sociedade, o inconsciente, o pensamento.

Voltando ao texto base do presente artigo, "Estrutura" em linguística, é também importante destacar que Benveniste aponta que há, no contexto das reflexões em vários campos da ciência, nessa época, uma substituição do atomismo por estruturalismo, e do individualismo por universalismo (podemos perceber que aqui ele acompanha, literalmente, Troubetzkoy). Esse deslocamento apontado pelo autor toma diferentes contornos nas diferentes realidades em que a linguística vai se inserindo e se desenvolvendo. Aliás, em Tendências recentes em linguística geral (de 1954), ele já havia dito que a noção de estrutura toma contornos diferentes na Europa, onde a noção de estrutura foi lida como sistema distintivo e solidário. $\mathrm{Ou}$, como dizia Troubetzkoy, que estrutura jamais é uma simetria completa, mas uma tendência ao equilíbrio e à "tendência"; ou nos Estados Unidos, onde estrutura foi lida como capacidade distributiva dos elementos via associação ou substituição. Benveniste aponta ainda que Bloomfield, ao desenvolver a noção de estrutura da língua, fala em "organização".

Pois bem, mas e o que seria, afinal, uma leitura estrutural da língua?

Uma primeira consideração que nos parece importante fazer é que se se atribui a Saussure a fundação de uma linguística estruturalista, ou antes, atribui-se a ele a paternidade da linguística, essa atribuição é, como sabemos e acabamos de retomar pelo conjunto de datas, eventos, publicações e discussões que apontam que a ideia de estrutura estava latejando na Europa desde o final da década 1920, mas particularmente toma fôlego na França nas décadas de 1950 e 1960, essa atribuição de fundação/inspiração é retroativa. Nesse sentido, será igualmente num movimento retroativo que nos cabe sublinhar uma leitura dos efeitos dessa onda - porque parece difícil mesmo nomear se estrutura foi um operador, um movimento, um método, uma linha, uma abordagem, 
um ponto de vista, ou sabe-se lá mais o quê. É difícil e arriscado categorizar. Em geral, não se pensa diretamente em Benveniste como um estruturalista. Não, não se pensa. Vem antes à cabeça nomes como o de Jakobson, o de Troubetzkoy, o de Hejlmslev, o de Bloomfield, e até, um pouco inadvertidamente, o de Saussure. Mas o próprio Jakobson é tão defensor da ideia de funcionamento (como vimos, nas bases fundadoras do Círculo Linguístico de Praga), por exemplo. Troubetzkoy, apontado como o grande mentor da excessiva abstração empreendida pela fonologia, falará em uma fonoestilística que escapa da regularidade da fonologia e pressupõe uma singularidade no falar dos indivíduos. Sublinhamos essas informações para lembrar que esses mesmos autores que temos como típicos estruturalistas tinham uma visão aberta que lidava ao mesmo tempo com funcionamento do sistema e com singularidade de sua atualização. Ou seja, cabe-nos realmente perguntar o que entendemos por estrutura ou por estruturalismo cada vez que lemos, ouvimos, falamos, escrevemos ou, principalmente, quando criticamos esses termos.

$\mathrm{E}$ isso nos leva a dizer (embora não nos pareça que ainda hoje fosse preciso fazê-lo) que também se comete muitas vezes o equívoco de uma apressada interpretação da noção de estrutura como fixa, rígida. Como a história das ideias no decorrer do século XX mostra, vários expoentes da vanguarda estruturalista, no decorrer de sua reflexão, revisaram suas próprias proposições. E, com isso, ressignificaram o conceito de estrutura em suas propostas.

Nesse sentido, são ilustrativas as contribuições de Deleuze ao formular os princípios que "explicam" no que se reconhece um estruturalista. Esse autor, por exemplo, irá inserir na noção de estrutura a variável da "casa vazia". A noção de casa vazia de Deleuze mostra, conforme apontaremos mais abaixo, que há algo na estrutura que comporta a falta.

Igualmente, se lermos razoavelmente o texto de Michel Pêcheux Estrutura ou acontecimento - sim, Pêcheux, sim, estrutura - encontraremos lá o analista de discurso, o marxista, o filósofo, dizendo - já no começo da década de 1980 - que a língua é estrutura mas é também acontecimento! Nesse belo livro da fase final de suas reflexões, Pêcheux revê a posição de linguistas, historiadores e filósofos materialistas através de uma instigante crítica: após apontar que se ficou um tempo significativo apostando na explicação das leis de tipo científico-galileanas (PÊCHEUX, 1997, p. 41), o autor, assim como Deleuze, também faz alusão à ideia de falta, utilizando a noção de furo no real (PÊCHEUX, 1997, p. 43). Diz o autor:

[...] a revolução cultural estruturalista não deixou de fazer pesar uma suspeita absolutamente explícita sobre o registro do psicológico [...]. Esta suspeita não é, pois, engendrada pelo ódio à humanidade que frequentemente se emprestou ao estruturalismo; ela traduz o reconhecimento de um fato estrutural próprio à ordem humana: 0 da castração simbólica. (PÊCHEUX, 1997, p. 46, grifos nossos). 
E, mais adiante, ele vai ainda dizer que isso obriga

[...] a pesquisa linguística a construir procedimentos capazes de abordar o fato linguístico do equívoco como fato estrutural implicado pela ordem do simbólico (PÊCHEUX, 1997, p. 51).

E ouvimos nossos tantos contemporâneos ainda repetindo muitas vezes que estrutura é rigidez, é fixidez, que estrutura é estática, que estrutura é sempre fechada.

E aqueles, entre os quais nos incluímos, que se identificam com interpretações benvenistianas, saussurianas, jakobsonianas ou lacanianas ficam um tanto nervosos com o tal estruturalismo estático e hermético. Lemos em Lacan (2003), para quem os sintomas podem ser considerados estruturais ou clínicos, que o inconsciente funciona à moda da linguagem. Em Saussure lemos que a faculdade da linguagem, essa que é a capacidade simbólica, que é heteróclita e multiforme, que está a cavaleiro de diferentes domínios é estática??? Lemos no Curso de Linguística Geral que a linguagem é ao mesmo tempo física, fisiológica e psíquica e concluímos que ela é fixa??? No mínimo esquisita, senão redutora, a forma que estivemos lendo esse tal de estruturalismo! Ainda que os excessos de um cientificismo binário tenham nos feito encontrar, por exemplo, um Jakobson algumas vezes meio "estruturalista demais”, meio binário demais, não se pode encapsular aí toda a reflexão do autor. Afinal, é esse mesmo inquieto pesquisador que propôs uma leitura para Les
Chats de Baudelaire, em coautoria com Lévis-Strauss, para o segundo número da revista L'Homme (aquela fundada em 1961 por Lévi-Strauss com a ajuda de Benveniste). Esse mesmo Jakobson nos diz que todos falamos um idioleto (ou seja, uma apropriação da língua por meio de um estilo único, não classificável em um modelo rígido); esse mesmo Jakobson aponta que a função poética, baseada na preponderância do eixo paradigmático sobre o sintagmático, produz, por meio de um estilo metafórico, efeitos imprevistos e sempre renovadores da língua.

E, voltando especificamente a Benveniste, nas "Últimas Aulas no Collège de France", percebemos ali um autor retornando às questões de base sobre linguística geral por sua própria escolha (diferentemente de Saussure, que teve de assumir aulas de linguística geral na Universidade de Genebra, em função do afastamento do titular do curso). Aliás, Benveniste fala de sua herança saussuriana em quase todas as aulas desse seu último curso, ministrado entre 1968-1969. Pode-se ler, por exemplo, na terceira aula:

A língua é vista, ao mesmo tempo, como conjunto de signos e como um dos sistemas semiológicos. Assim é definida a estrutura e o pertencimento da língua; sua natureza "significante" e a dependência em que ela se encontra em relação a outros sistemas de signos (BENVENISTE, 2014, p. 100, grifos nossos).

Que os signos são abstrações e que não sobrevivem senão em relação com os outros signos dentro de um sistema, isso Benveniste está dizendo que bebeu em 
Saussure ${ }^{6}$. Que a língua seria "apenas" o principal dos sistemas semiológicos, até aí Saussure também foi. Mas, visivelmente, o passo além dado por Benveniste foi a questão da interpretância (BENVENISTE, 2014, p. 111). É nessa via que a noção de língua como sistema é lançada a uma não-unicidade, o que permite a Benveniste avançar nas discussões propostas anteriormente pelo pai da linguística.

Nesse sentido, (re)ler os autores na fonte, obviamente, é fundamental. Mas ler releitores contemporâneos igualmente o é. E o filósofo Dany-Robert Dufour é um deles. Um filósofo que lê muito bem os linguistas, aliás.

Dufour (2000), em Os mistérios da trindade, propõe os termos unário, binário, trinitário para repensarmos as noções de estrutura da língua, do inconsciente e da sociedade. No que diz respeito a sua interpretação do campo da linguística, a reflexão desse autor pode nos ajudar a avançar na compreensão da passagem da noção de sistema à de estrutura, apontando como alternativa a saída trinitária da interpretação, da enunciação e do discurso.

Antes de elaborar suas formulações acerca do trinitário, Dufour lembra que o estruturalismo representou a vanguarda do binarismo nas ciências do Homem (DUFOUR, 2000, p. 27). Atribuindo essa lógica a um movimento datado (há quem não concorde com essa opinião do filósofo francês), ele irá dizer que o operador binário organizava o caos tornando teóricos diversos objetos empíricos. $\mathrm{O}$ autor (DUFOUR, 2000, p. 29) aponta o aforismo lacaniano "o inconsciente é estruturado como uma linguagem" como modelo ou carro-chefe desse estatuto epistemológico. A ideia de casa vazia de Deleuze é então acionada por Dufour para abalar a lógica binária. Mas aí não está tudo. Dufour nos diz (já desde 1988, em Le bégaiement des maîtres) que o estruturalismo, na verdade, é de base unária. E, no terreno benvenistiano, ele vai destacar (DUFOUR, 2000, p. 36) que isso está representado no axioma "é eu quem diz eu".

Por isso o texto do Gilles Deleuze citado por Dufour é tão instigante. Mas, ainda assim, esse clássico artigo, que propõe uma leitura crítica à proposta estruturalista, não resolve todos os impasses de quando se tenta explicar Em que se pode reconhecer o estruturalismo? (DELEUZE, 201077). Repare-se a drástica afirmação de Deleuze: "é com razão que se apresenta a linguística como origem do estruturalismo" (DELEUZE, 2010, p. 221). Após afirmar que a ciência da linguagem serviu de modelo para que analogicamente outros campos também produzissem problemas, métodos e soluções à moda da linguística, o autor faz uma nova e impactante afirmação: Se o estruturalismo se estende a outros domínios, não é mais por analogia para instaurar equivalentes, mas porque, antes de tudo, "só há estrutura daquilo que é linguagem”. Percebe-se aí não mais apenas um centramento ou uma crítica ao pretenso protagonismo da linguística na "origem" do modelo estrutural, 
mas o próprio apontamento da condição simbólica de todos os campos que tentam explicar a lógica de constituição do humano. Olhemos, portanto, mais uma vez quais seriam os "cinco mais um" critérios propostos por Deleuze para se reconhecer o estruturalismo:

1. O simbólico: toda estrutura é ao menos triádica, sem o que ela não "circularia", não se movimentaria;

2. A posição: uma estrutura é sempre topológica, um sentido nela é uma posição. $\mathrm{O}$ sentido gerado é efeito de linguagem, efeito de posição;

3. O diferencial e o singular: relações distintivas numa estrutura estabelecem a singularidade;

4. O diferenciador, a diferençação: há a diferenciação dos termos (enquanto possibilidade virtual) e a diferençação dos efeitos (atualização da diferença) - seguindo a máxima "real sem ser atual, ideal sem ser abstrata" (DELEUZE, 2010, p. 231)

5. Serial: a relação com a série é o que bota a estrutura em movimento/deslocamento;

6. A CASA VAZIA: "único lugar que não pode nem deve ser preenchido, nem mesmo por um elemento simbólico" (DELEUZE, 2010, p. 244). O que está em jogo aqui é o lugar relativo dos elementos e o valor variável das relações.
Será a partir da consideração desse sexto elemento - a casa vazia - que Dufour (2010) aponta para uma interpretação do trinitário. No terreno da linguística, é, então, que ele recorre a Benveniste e sua leitura das posições da tríade eu-tu/ele na língua.

$\mathrm{E}$, partindo dessa reflexão acerca do trinitário na língua e passando pelo dispositivo do Aparelho formal da enunciação tal como proposto por Benveniste, perguntamos: o Aparelho formal da enunciação, presente em artigo proposto por Benveniste menos de dez anos após "Estrutura" em linguística, seria um modelo - teórica ou metodologicamente - estrutural? Nada nos deveria levar a apressadamente negar essa possibilidade de leitura. Com isso se pode dizer que há na proposta benvenistiana a pressuposição da noção de sistema - ou estrutura. O problema maior não parece a discussão sobre se Saussure, Jakobson, Benveniste, Lévi-Strauss, Foucault, Lacan, Barthes e outros tantos grandes eram ou não estruturalistas, ou o quanto eram, ou até quando foram. Sem dúvida, essa seria uma discussão sobre os desdobramentos do movimento estruturalista. A questão maior, pelo menos aquela que parece ser mais produtiva para uma reflexão sobre o estatuto epistemológico dos sistemas simbólicos em geral, e da língua em particular, é nos perguntarmos o que entendemos por estrutura. Nesse sentido, nos aliamos totalmente a Dufour: o ponto de vista desde o qual se considera o sistema em questão pode 
ser concebido como unário, binário ou trinitário. O modo como olharemos para esse sistema - ou estrutura - é que vai mudar. Lidar com o objeto - no caso, a linguagem, a língua, ou a fala - de forma unária, binária ou trinitária é que vai fazer a diferença mais significativa.

É por esse motivo que autores como Milner (1987), Normand (2009) e Flores (2009) vão partir de uma profunda reflexão sobre a língua e, em dado momento, percebem que, ao proporem o estudo do sistema considerando o sujeito que fala, acabam por entrar em cena questões do próprio linguista. Porque tem algo que sempre escapa. Algo que vai além do sistema, da estrutura, da língua, mas que está pressuposta na ideia de sistema. Tem esse algo a mais que passa pela noção de não-todo, de casa vazia, de falta, de inconsciente, de entremeio que não tem como se contornar. Ou melhor dizendo, tem. E é justamente por isso que a linguística é ainda tão eficaz em sua formatação científica higienicista.

Após esse mergulho que partiu do texto benvenistiano "Estrutura" em linguística e buscou tentar investigar a conjuntura em que o linguista sírio produziu suas brilhantes reflexões, nossa sensação é a de que os tempos vindouros serão ainda permeados por muita inquietação. Mas essa inquietação é também possibilidade de encararmos nossos maiores desafios. Um deles seria (re)pensar o Aparelho formal da enunciação. Esse conhecido dispositivo benvenistiano é notadamente de base estrutural, e, se concebido numa leitura trinitária, pressupõe a ideia de falta, de casa vazia, para funcionar. Portanto, as variáveis presentes em todo o ato de fala - eu, aqui e agora - estarão sempre submetidas a uma instância que está fora do alcance da linguística, ou de qualquer ou campo científico específico. Parece-nos importante lançarmos luzes sobre como lidar com essas variáveis a partir de uma concepção que suporte a ideia de que algo que passa por um corpo que experimenta os efeitos da linguagem não cabe em uma análise que se restrinja a formas binárias da lógica da língua. Afinal, se consideramos o Aparelho formal da enunciação como uma construção estruturalmente triádica (e, portanto, simbólica) ele estará sempre remetido a um evento inapreensível que é a enunciação (o agora de cada ato de fala), e seus efeitos em outro Aparelho formal da enunciação igualmente remetido ao não-todo. Caberá, então, ao linguista de nossos tempos decidir se sua abordagem dos estudos da língua e da linguagem comporta uma leitura que pressuponha o estudo da estrutura de forma não totalmente explicável nos limites de uma visão unária ou binária da língua. 


\section{The notion of structure in Linguistics: a shocking (and decisive) repercussion}

\begin{abstract}
The present paper starts at the reading of Structure in Linguistics, originaly published in 1962, but also present at Emile Beveniste's Problems in General Linguistics. The goal of this work is to understand the fortuity of this text elaboration, focusing mainly at the European intelectual movement that comprehend the 1950s and the 1960s in order to reflect on the epistemological status of the term structure in Linguistic Studies during the referred period.
\end{abstract}

Keywords: Linguistics epistemology. Structure. Structuralism.

\section{Notas}

1 Disponível em: <https://www.en-attendant-nadeau.fr/2018/07/03/levi-strauss-jakobson-correspondance/ $>$.

2 Testemunho de Lévi-Strauss sobre Benveniste no livro Correspondance 1942-1982 (JAKOBSON \& LÉVI-STRAUSS, 2018).

3 O psicanalista francês Jacques Lacan, em 1956, solicitou a Benveniste colaboração para o primeiro número da revista La psychanalyse. $\mathrm{O}$ artigo então produzido pelo linguista não é nada menos que "Sobre o sentido antitético das palavras primitivas", publicado depois em Problemas de linguística geral I. Lacan, anos mais tarde (1970), em Radiofonia, comenta sua decepção com o texto benvenistiano, apontando a dificuldade de a linguística considerar o inconsciente, ao comentar que "Essa carência do linguista, pude verifica-la por uma contribuição que pedi ao maior que existiu entre os franceses, para ilustrar o lançamento de uma revista de minha criação" (LACAN, 2003, p. 408).
4 Trata-se das últimas aula proferidas por Benveniste no Colège de France, nos anos de 1968-1969.

5 Conforme se pode ler na entrevista que Krystyna Pomorska faz com Roman Jakobson em Diálogos (JAKOBSON, 1985, p. 31).

6 Milner (2000, p. 146) lembra que Benveniste claramente buscou na linguística estruturalista a noção de sistema/estrutura como pura abstração, ao analisar fonemas conjecturais do indoeuropeu.

7 Texto publicado originalmente em 1972.

8 Deleuze ilustra diferenciador e diferençação com o exemplo do estatuto dos fonemas nas diferentes línguas: os fonemas existem (diferenciador) independente das relações que travam em cada língua (diferençação).

\section{Referências}

BENVENISTE, É. "Estrutura” em linguística. In: Problemas de linguística geral I. Campinas: Pontes, 1991.

Tendências recentes em linguística geral. In: Problemas de linguística geral I. Campinas: Pontes, 1991.

Estrutura da língua e estrutura da sociedade. In: Problemas de linguística geral II. Campinas: Pontes, 1989.

Semiologia da língua. In: Problemas de linguística geral II. Campinas: Pontes, 1989.

. O aparelho formal da enunciação. In: Problemas de linguística geral II. Campinas: Pontes, 1989.

Últimas aulas no Collège de France (1968-1969). Trad.: Daniel Costa da Silva et. al. São Paulo: Ed. da Unesp, 2014.

DELEUZE, G. Em que se pode reconhecer o estruturalismo? Trad.: Hilton F. Japiassú. In: A ilha deserta. São Paulo: Iluminuras, 2010.

DOSSE, F. História do estruturalismo - $O$ campo do signo. Trad.: Álvaro Cabral. Campinas: Ed. da Unicamp, 1993. 
DUFOUR, D.-R. Os mistérios da trindade. Trad.: Dulce Duque Estrada. Rio de Janeiro: Companhia de Freud, 2000.

. Le bégaiement des mâ̂tres. Strasbourg: Editions Arcanes, 1999.

FLORES, V.N. O linguista e a linguística no CLG. Nonada, Porto Alegre, v. 1, n. 12, p. 28-41, 2009.

JAKOBSON, R.; POMORSKA, K. Diálogos. Trad.: Elisa Kossovitch. São Paulo, Cultrix, 1985.

JAKOBSON, R.; LÉVI-STRAUSS, C. Correspondance 1942-1982. Trad. par Patrice Maniglier. Paris: Éditions du Seuil, 2018.

LACAN, J. Radiofonia. In: LACAN, J. Outros escritos. Trad.: V. Ribeiro. Rio de Janeiro: Jorge Zahar, 2003. p. 400-447.

MILNER, J.-C. O amor da língua. Trad.: Angela Jesuino. Porto Alegre: Artes Médicas, 1987.

. Introducción a una ciencia del lenguaje. Buenos Aires: Ediciones Manantial, 2000.

NORMAND, C. Convite à linguística. Trad.: Cristina Birck et al. São Paulo: Contexto, 2009.

PÊCHEUX, M. O discurso: estrutura ou acontecimento? Trad.: Eni Orlandi. Campinas: Pontes, 1997.

SAUSSURE, Ferdinand de. Curso de Linguística Geral. São Paulo: Cultrix, 1974.

TOLEDO, D. Círculo linguístico de Praga: estruturalismo e semiologia. Porto Alegre: Globo, 1978.

TROUBETZKOY, N. Principes de phonologie. Paris: Klincksieck, 2005. 